\title{
Moving Beyond "Outreach": Reflections on Two Case Studies of Community Library Services in South Africa Genevieve Hart ${ }^{1}$
}

Department of Library and Information Science, University of the Western Cape ghart@uwc.ac.za

Received: November 2011

Accepted: September 2012

The paper examines the contribution, real and potential, of public libraries in South Africa to social inclusion by means of so-called outreach programmes. The discussion is grounded in two case studies of two community libraries - one rural, one urban. The argument is that what are often viewed as "outreach" programmes point the way to new models of library and information services (LIS), which will be meaningful to far more than the present tiny minority of South African library users and which thus might fulfil the vision of the LIS Transformation Charter of the National Council of Library and Information Services (NCLIS) (2009). The paper explores the meaning of library outreach in the international literature and then uses the insights gained from the outreach literature to examine the two cases.

Keywords: Library outreach services; South Africa; community libraries; public libraries; social inclusion; case study

\section{Introduction}

This paper reflects on two case studies in order to examine the contribution, real and potential, of South African public or community libraries to sustainable development and to social inclusion. The author has reported on one of the case studies before (Hart 2010; 2011) and, inevitably, there will be some overlap with her previous writing. However, the angle in this paper is different and it adds insights from the second site.

Both case sites are the product of outreach initiatives. The paper argues that what are often viewed as "outreach" programmes point the way to new models of library and information services (LIS), which will be meaningful to far more than the present tiny minority of South African library users and which thus might fulfil the vision of the LIS Transformation Charter of the National Council of Library and Information Services (NCLIS) (2009). The Charter's vision for the future is that libraries will be "within reach of all", "places for everyone" and "forces for social cohesion and justice". It endorses a developmental model of community library "in keeping with the socio-economic context and UNESCO's Millennium Development Goals". The vision, thus, is of an activist public librarianship that is a catalyst or agent of social change.

\footnotetext{
${ }^{1}$ Genevieve Hart $(\mathrm{PhD})$ is an Associate Professor in the Department of Library and Information Science, University of the Western Cape.
} 
While acknowledging the work of the many dynamic public librarians in South Africa, the Charter points out that less than 10 percent of South Africans at present belong to public libraries, that they are unevenly distributed, that school learners account for 70 percent of their usage, and that 74 percent of public libraries lack Internet access. It suggests that the contribution of libraries to social cohesion and development is not widely understood and that libraries are probably viewed by most South Africans as irrelevant collections of books for the educated, the middle class and students. Evidence for this comment might possibly lie in the burning down of public libraries in so-called service delivery protests in the past few years (Library and Information Association of South Africa 2010). The target of the protests was probably the local authorities but the destruction of the libraries indicates the lack of value placed on books and libraries (Jansen 2011).

Any discussion of public libraries in South Africa has to consider their socioeconomic context. The so called poverty gap has been described as one of the worst in the world with more than $48 \%$ of South Africans living below the poverty line (University of Cape Town. Development Policy Research Unit 2010). The Human Development Index (HDI) of the United Nations adds two factors to household income in its assessment of the quality of life of a country's citizens: life expectancy and education. Using these measures, Butler (2004: 66) points out that South Africa's HDI compares badly with many other countries with lower GDPs. It comes 107 out of 173 countries.

"Outreach" in the South Africa community library context must surely aim at building the community's social capital, which is required for socio-economic development. On its PovertyNet web site, www1.worldbank.org/prem/poverty.scapital/whatsc/htm, the World Bank points to the increasing evidence that social capital is crucial for societies to prosper economically and for development to be sustainable. Networks of relationships among persons, companies, institutions and civic organisations enable a society to function effectively and to move beyond poverty. This paper rests on the premise that, given the present underuse of libraries by South African adults, it is only by outreach that libraries can join and build these networks.

\section{Public library outreach}

A perusal of the library outreach literature reveals at least four, often intertwined, perspectives:

- Outreach as promotion and marketing. There are warnings that, unless libraries raise their profile and advertise their value, they might not survive (for example Block 2000; Hill 2004).

- Innovative ways to talk to library customers - for example, via social media like Facebook or virtual reality as in Second Life (for example Future intersections 2006). This thread is characterized by catchy titles such as 
"Your place or mine" and "Your space, not myspace". Academic librarians talk of ways of reaching students "on their own turf" (Del Bosque \& Chapman 2007).

- Specialist information services extending their services beyond their walls and traditional clientele. Examples are health libraries proactively reaching out to people in isolated rural areas, primary care workers in their workplaces, and patients at home (Kambeitz 2002; Robinson \& Bawden 2007; Duesing 2009).

- Proactively extending services to a wider range of people - to what are often called "non-traditional" library users. These are people who have never been into a library perhaps. In the academic library context, outreach might well mean extending services to under-represented minorities such as Hispanic students or foreign students (for example Aigular \& Keating 2009). The concepts of what a library does might well also be extended. Zettervall (2011: 50), for example, cites examples of an American public librarian audio recording prisoner parents reading children's books. The CD and the book are then sent for free to their children at home.

The focus of this paper is on the last three categories and on public libraries. Immediately the need to interrogate the meaning of "non-traditional" and "minorities" is clear. After all, in developed countries like Australia, the USA, and the UK, from where most of the writing on outreach comes, more than 50 percent of the population are registered library members. Outreach librarians are appointed to build relationships with under-represented "minorities". In South Africa, as stated above, only a small minority of the population belongs to or uses libraries and, as mentioned above, at least half might be described as "poor" so the concept of outreach has to be viewed through a different lens perhaps. Some of the international writing assumes that setting up a library in a low-income community is "outreach" which might surprise the many South African librarians who are working in historically disadvantaged townships, where poverty is the norm.

It can be assumed that poverty is common to the many of the minority groups referred to so often in the international literature; and, indeed, it was the desire to serve the poor that informed the mission statements of many of the early library outreach programmes. Access to books, literacy and education, as provided by public libraries, was seen as a means of upliftment. In 1983 Wiebel analysed the development of library outreach in the USA from 1960 to 1975 . She linked it to the federal government's War on Poverty programme in the 1960s and then showed how changes in government and the end of federal funding for poverty alleviation outreach projects in the 1970s led to shifts in emphasis. As part of the War on Poverty, library outreach programmes in the 1960s in the US explicitly targeted urban blacks and rural poor whites, such as those in Appalachia. Wiebel identifies four service styles in the early years: attempts to make the traditional services relevant to a community; participation in the life of the community by library staff; 
neighbourhood depots or storefront services; and the extension of services through cooperation with other agencies. Although all four approaches shared the belief in close community interaction, the creation of a "climate for use" and intensive reader services, Wiebel (1993: 15) comments that those libraries that participated in the life of a community, rather than merely trying to extend their traditional services, eventually transformed their priorities from "library materials to human interaction".

The human element crucial to library outreach is highlighted in Muddiman's review of research in the 1990s in how working class and disadvantaged people in the UK conceive of public libraries. It holds lessons for South African librarians. He points to evidence that, in contradiction to the rhetoric that the library is a place "for all", the institutional culture of public libraries excludes many working class and disadvantaged people. These groups, as well as black and ethnic minorities and teenagers, tend to see the library as a place where the middle class gets books to read (1999: 187). Muddiman concludes that more research is needed in the perceptions of non-users in disadvantaged groups and that "newer social roles" for libraries are needed. It would be interesting to see whether libraries in the UK have responded to such comment and have indeed found new roles with wider appeal since the late 1990s. The rise of public library Internet services since Muddiman's review might well have facilitated shifts in attitudes and use, for example.

The outreach literature of the past 10 years reveals the diversity of outreach programmes and confirms the trend, predicted by Wiebel in 1983, towards targeting services to so-called "special populations". There are reports of outreach to ethnic minorities, immigrants, prisoners and young people in detention centres, the hospitalised, the housebound, the homeless, the disabled, GLBT (gay, lesbian, bisexual and transsexual) people, rural inhabitants, the working class, disaffiliated teenagers, and, so on. The strategies to break down barriers are also diverse - for example mobile libraries, container libraries, books by mail projects, deposit collections, use of social media and other ICTs such as cable TV, mobile phones and toll free phone services.

There are however some common threads across all the reports such as:

- A willingness among outreach advocates to confront socio-economic realities, not as bystanders but as change agents

- Collaborating and networking with other social agencies

- A belief that libraries do, in Gieskes's words, "matter to poor people" (2009). Watkins (2000) labels the inadequate provision of libraries to low-income communities as "intellectual theft" as it robs the community members of access to full citizenship - to the detriment of society at large

- Openness to community participation. Communities, it seems, need to be given autonomy to make decisions on the kind of library services they need. Mehra and Srinivasan (2007) present a framework for library and community 
convergence, which their research shows enables a library to participate more fully in culturally diverse communities

- Respect for the communities targeted for outreach. One outreach librarian is reported to have insisted on architects changing the design of a new library in a low-income immigrant community in Denver, USA, from a building that looked like a prison to one that says "we care" (Fearless capacity 2011)

- Recognition that just transferring traditional public library services will not work. "Locally relevant and empowering "services must be offered (Mehra \& Srinivasan 2007: 1).

Overall, the outreach literature is characterised by the belief that libraries are agents for social inclusion and social justice. Much of the outreach writing might be described as enthusiastic advocacy. Indeed, the key attribute of an outreach librarian is, according to one author, a "high level of passion" for social justice (Kambeitz 2002: 97). Whether services to the poor matter to all public library staff is questionable, however. One of the findings of the survey of public librarians conducted in 2008 by the American Library Association Office for Literacy and Outreach Services was that 70 percent of the respondents knew of no libraries successfully providing services for the poor (Gieskes 2009: 54). In defense of her respondents, the author does acknowledge their comments on the lack of guidance or leadership from their professional associations.

\section{Outreach and social inclusion in two South African case studies}

It is hoped that the preceding review of the outreach literature might provide a frame to examine the author's studies of two LIS in South Africa, both of which might be regarded as outreach services. The question that hovers over the discussion, however, is over the appropriateness of the frame for the South African context.

The author's case studies of each site are independent of each other; each has its own objectives and research questions. But reflection has revealed the concept of outreach as one of the points of intersection between the two studies. Both sites were established by their parent libraries to provide services to neglected communities, one in a rural ex-homeland area, to be called Site $\mathrm{A}^{2}$ in this paper, and one in a black township on the outskirts of Cape Town, to be called Site B.

Other points of intersection include the following, all of which resonate with the preceding discussion and which will be alluded to in the course of the discussion:

- Both sites serve disadvantaged black communities, which today still live with the heritage of apartheid land allocation and group area policies, as will be shown below

\footnotetext{
${ }^{2}$ Names of the sites and participants are withheld to fulfill assurances of anonymity
} 
- Private benefactors have played a crucial role in both libraries. Site A was established with donor funding and Site B still relies on private funding, which has been "guaranteed" until 2017

- Both rely on partnerships among a diverse array of people and bodies -their parent libraries, their library authorities, different government departments, private corporations, NGOs, and, so on

- Both are satellite libraries to larger public libraries, which in their turn fall under a provincial or metropolitan LIS and authority

- Both rely on the enthusiasm and leadership of individuals on the ground

- Both have been recognised by their parent bodies and librarian peers - with both receiving awards from their provincial authorities for their community oriented services.

\section{Site $A$}

Site A, which has been described in previous articles (Hart 2010; 2011), is made up of six dual-use school-community libraries scattered across an ex-apartheid homeland. The six libraries are closely connected with one another as evidenced in the camaraderie and constant communication among their six librarians and they are viewed as a unit by the provincial library service, as shown in their winning of that library service's "Community Library of the Year" award in 2007. As the political scientist Butler (2004: 135) points out, the South African ex-homelands are not "rural" at all but rather immense and densely peopled townships placed far from economic opportunities. By the early 1980s, the population of Site A's region had grown tenfold since its establishment in 1974 - leading the Surplus Peoples Project to label it a "peri-urban slum in the middle of nowhere". The case study region, now integrated into one of South Africa's nine provinces, is the poorest region in the Province. It is now divided between two municipalities and its 910 square kilometres is home to about 1.3 million people.

Because of the poor transport infrastructure and the wide spread of the population, access to the central public library downtown is difficult. This is why in 2001 the provincial public library service approached the international donor for help in setting up six community libraries in remote schools. The six schools are about 50 minutes drive away from the business and commercial hub. Two criteria were used in the choice of schools: their remoteness and the existence of a library room, even if bare and disheveled. The donor support came to an end in 2004 and at present the six libraries are staffed and maintained by the provincial public library service, which falls under the provincial Department of Arts and Culture. From time to time the school library support service of the provincial Education Department supplies some curriculum related books and its school library advisors try to keep in touch with the six libraries. However, only nine percent of schools in the province have functioning libraries and, with over 150 schools under each advisor's wing, they admit that they tend to benignly neglect the dual-use libraries. 
The main question guiding the case study of Site A was the working of a dual-use library based in a school. The purpose was to investigate if such a model could help solve the backlogs in provision of school and public libraries. As mentioned earlier, two articles have been published earlier which described the research methodology and explored these questions (Hart 2010; 2011). However the site offers valuable insights for the themes of this paper, outreach and the role of libraries in social inclusion. The funding proposal for the international donor which was drawn up by the provincial library service echoes many of the themes in the outreach literature. Thus it describes its aims as:

- increasing numbers of libraries and bringing them closer to the people

- providing electronic access to information

- improving study facilities

- broadening the scope of services offered and

- teaching people how to use information to their benefit, this creating an environment supportive of sustained economic, social and civic development.

The document spells out quite precise outcomes with regard to their public users, for example: increasing library membership by 20 percent; increasing literacy rates by five percent; and increasing by 20 percent the number of people accessing government and community information. As far as the author knows, there has been no attempt to evaluate if these outcomes are being achieved.

Ironically, despite the emphasis on access in the funding proposal, access to the libraries is difficult, with all but one tucked away at the back of the schools, none with any signboard outside the schools and locked school gates often keeping community members at bay. A certain ambivalence in the schools towards allowing open access might partly explain the rather low usage of the libraries by the adults in the surrounding villages that was documented over the two weeks of the study. Observation in the course of the week in one library recorded a steady trickle of young people, recent school-leavers still out of work and NGO workers. They came in to read the newspapers and magazines, play chess, look up information on the one work station able to access the Internet, and type up reports. Two other regular groups were a small group of women in a literacy class hosted by the school and a nursery school group. Although many might believe that this usage justifies the existence of the dual use libraries, the low use does raise the question of sustainability. The Public Library District Manager acknowledges the low use by adults, saying:

It's mostly used by the schools. But you know it's something that happens in our black communities. They - the adults are not using libraries. We are still trying to teach them that they use libraries for all their information needs. But it's the culture that is going on in our black community. 
The staff of the six libraries - all on temporary contracts and only one with professional librarian qualifications - are passionate about their work as evidenced in this extract from an interview:

I feel, to be a librarian ... I'm passionate about it. Yes, that gives me a passion, because if you talk about the library, my ears are open and I have to listen attentively towards what you are saying about the library. Even if there is something wrong or misinterpretation, so I have to correct. I have to make sure that I correct the very same person and motivate the person towards, to use the library. Yes, I'm really passionate about this position.

But, on being asked about the low usage by the adults in the surrounding villages, this participant reveals some frustration over his efforts to market the library thus:

They don't use the library, yes. We try to give them things that will motivate them to the library. We give them the magazines, give them things that you'll think they're not longer useful for the library. Things that you'll say will benefit them.

I got the taxi here, use my feet towards the library, it's about $900 \mathrm{~m}$, about a kilometer. I meet with these two ladies on the left hand side. Talk to them. They will tell you they are busy maybe meet them next time. Then you go to other people maybe you give them pamphlets about the library. You invite them to the library. But then you won't even see one person in that month.

In these extracts there are echoes of Muddiman's study in the UK of perceptions of public libraries. He quotes a participant in a group interview as saying: "I think you're flogging a dead horse here because people in this room don't really use a library and whatever you call it you're not going to get us through the door. It's because we don't read ...." (1999: 184). Muddiman's response is that it is the perceptions of the library as a place just for reading that acts as the barrier. The Site A librarian's description of marketing "the library", as well as data gathered in the author's observations over two weeks, again echoes Muddiman's comment that community members and library staff cannot conceptualise their needs in anything other than existing library provision. This point will be returned to later as it is central to the discussion of the meaning of outreach.

\section{Site $B$}

Site B is situated in a relatively small township in Cape Town of about 38,000 people, many of whom have moved there in search of work from the Eastern Cape Province since 1996. It owes its establishment to Apartheid land policies whereby black families were removed from a nearby so-called white farming area. It was 
recognized formally as a township by the city in 1992 and its population is estimated to have tripled since 1996. Ninety percent of residents live in shacks in rented small subdivided plots in inaccessible streets. Unemployment is thought to be at 60 percent.

The case study at Site B is still ongoing. Its purpose is to investigate the role of public libraries in building social capital. Interviews have been conducted with several role-players; observations have taken place; and documents have been analysed. All these have highlighted the issue of outreach, the theme of this paper. Other components of the case study are a Masters degree project investigating how a library can help bridge the so-called digital divide in a disadvantaged community and a community survey that will look at the library in the context of other agents of social change in the township.

Site $B$, one of five satellite libraries in its library district, is the project of the largish library in the neighbouring predominantly white middle-class suburb. The Deputy Librarian at that library has taken the lead and driven Site B's development in the past 12 years. Its history can be traced back to the early 1990s when the librarian from another neighbouring library used to bring books to the township bus-stop in the boot of her car. The library was then set up in a room next door to the municipal housing office where it was burned down in a housing protest action in 1999. In 2003, a new standalone library was built by a foreign-based developmental NGO, responsible for many other projects in the township. It was handed to the city library service to be run as a satellite of the neighbouring suburb's library. Since then, in 2005 and 2010, with funds from the NGO and other bodies, two major extensions and an attractive children's park have been added for what the NGO fund-raising web site explicitly labels as "outreach" activities. The extensions include a large computer room with 14 workstations, a hall with an interleading kitchen for art classes and community meetings, smaller seminar rooms, a movie-viewing room, toilets and an office - all built round an attractive courtyard. According to one informant, an explicit decision was made to use high quality materials for the outreach section and to make it look "different" from the original library building. Its parent library skims off some of its own resources to run the satellite, with its Deputy and two staff members, residents of the Site B township, spending many hours a week there. The NGO has undertaken to provide R10,000 per month for stipends for other staff, including a computer lab supervisor, and for outreach activities until 2017. This date, according to the CEO of the NGO sponsor, is when the Deputy is due to retire. The NGO's faith in her leadership is such that it has linked its support to her continuing involvement.

Site B is, itself, the outreach project of its parent suburban library but a glance at its web site shows that it uses the term "outreach" to refer to its own diverse activities. According to the NGO's web site, clearly designed for fund-raising, the library 
employs 75 volunteers to run its "outreach" activities, which were attended by more than 34,000 participants last year. The outreach activities include computer literacy classes, literacy classes, a parents' support group, business skills workshops, an art club, formal tutoring, a homework club, a girls' club aimed at building girls' self esteem, a friendship club aimed at bringing children of different cultures together, and Xhosa lessons. The nature of these activities reflects the idealism and vision of the Deputy who, in one interview, describes the library as an "ideal arena for social development".

The author's field notes record how busy the library is. It has to be said that there is little sign of the traditional adult library activities of browsing the shelves and reading the newspaper so evident at its parent suburban library. In contrast to its parent, there are never queues at the book circulation desk. The draw seems to be the formal literacy and computer literacy classes and other support groups, the computers with their Internet connectivity, the photocopying facilities and the social and sociable activities. The library offers an attractive space for community meetings.

Site $B$ raises intriguing questions about the notion of outreach. The cover of the NGO's brochure for the 2009 fundraising appeal describes it as "no ordinary library". It claims that that its outreach activities distinguish it from other libraries and it is clear that they are what the funding appeal hangs on. Interviews with the Manager of the parent library and her deputy help unpack the concept of outreach in terms of the author's research interest in social inclusion. The Manager reveals that she for a long time regarded her own library as "perfect". But she began to revise her comfortable views when having to confront the notion of "transformation" for an article in a professional newsletter. In struggling with the meaning of transformation in post-apartheid South Africa, she realised, she says, that her library had limitations. Its reach and access to it were restricted. She began to shift her attitudes to public service and so supports her deputy's work at Site B.

In her interviews the Deputy acknowledges the freedom she has been given for what comes across as her life's work. But there are hints in interviews with other roleplayers that her passion for her work at Site B and, perhaps, her close working relationship with the sponsoring NGO might have been questioned. She admits to an interesting difference in perspective from her manager over the meaning of outreach. Whereas the Manager believes that the outreach funding and activities are separate from the library proper, she would prefer to see them integrated. She sees her outreach activities simply as library projects and is not interested, it seems, in any doubts over their appropriateness in terms of conventional library work. She simply sees the library as being about far more than books and reading. 
The Deputy reflects the belief in libraries as agents for social change that was identified in an earlier section as a strong theme in the international outreach literature. She refers to the parent library as a MCWL (middle class white library) and says that its continuing existence in post-apartheid South Africa can only be justified by its work in libraries such as Site B. She relies heavily on her team of volunteers, whom she describes as "tentacles of support". Her description of the role of volunteers both in the parent library and in Site B echoes social capital theory, which talks of "bridging" social capital, which can be created by interaction between two disparate communities (for example Alkalimat \& Williams 2001). Bridging ties transcend social and geographic divides - and can bring access to scarce resources. Thus, the volunteers recruited to Site B from the neighbouring suburbs both bring resources to Site $B$ and gain huge satisfaction from their work. Some of the funds raised by the Friends of the Library volunteers in the parent library are channeled to Site B.

A sobering note is sounded by the Manager on being asked about the challenges for Site B. She expresses concern over its sustainability. She wonders if the younger staff members share their enthusiasm and asks, "How do we build bridges when we retire?" The Deputy reveals a similar concern when she talks of the struggle to persuade library staff in Site B to come out from behind the circulation desk to serve the public. The author's field notes perhaps echo this concern as they record how the young staff members, both with professional qualifications, tend to stay at the counter doing clerical work and watching over the library. It is the volunteers who mix with the library customers to offer proactive library services. The field notes record a pointed question, which might resonate with Muddiman's comments on the barriers lying in the institutional culture of public libraries that were quoted above, "Don't we in library schools teach students what their real job is?"

\section{$4 \quad$ Conclusions}

The frame provided by the international outreach literature has indeed proved useful in analysing the two case study sites. The potential of both to play a dynamic role in the development of their communities and in social inclusion is clear. Site B is further along the road probably because of its visionary leadership and greater access to resources, both financial and human. It works hard at maintaining these resources by building its relationships inside and outside its immediate community.

However, the studies of both Site A and B raise questions over sustainability. While both at present rely on the generosity of their parent authorities, the long-term future of both is not certain. As long as they are regarded as outreach projects this doubt will continue. The Site A libraries are in many ways "perching" in their schools. They offer valuable services to their local schools but the Education Department provides no support for them. Their staff is appointed by their own Arts and Culture Department on year to year contracts and surely questions will sooner or later be 
asked about their low usage by the adult public. As reported in a previous publication, the Site A staff, though claiming to be passionate about being librarians, lacks a clear vision of what it is that a public library might offer their rural poor communities. They talk of marketing "the library" but seem to have no clarity on possible programmes. Leadership is needed from their parent services and from the LIS profession to build a framework for community participation and action, perhaps looking to international examples (for example Mehra \& Srinivasan 2007). As Muddiman (1999) points out, research is needed in relevant and empowering services that might break the preconceptions of the social role of public libraries.

Site B has clear vision and programmes targeted at specific needs, which probably explains its popularity. Yet, its future is not secure either. It is not yet integrated into the city's library services and is dependent on private funding. How much of its success is dependent on the leadership of the committed and idealistic Deputy?

However, perhaps the studies of the two sites do provide an answer to the questions over sustainability. They both suggest the need for a shift in thinking over the meaning of outreach. A glance at the NGO's advertising of Site B shows that whatever that is not book lending is seen to be outreach and that it is rather more special than traditional library work. And it is this use of the concept of outreach in opposition to conventional library services that is exploited to sell the library to possible donors.

The author would suggest that this is short sighted and in fact sells public librarianship short. A different approach would be to embrace so-called outreach activities into mainstream librarianship. In a society like South Africa, only if the institutional culture of public libraries changes to embrace the role of libraries in social inclusion by means of outreach activities will they have a future. Leadership and vision are required.

\section{$5 \quad$ References}

Aguilar, P. \& Keating, K. 2009. Satellite outreach services program to underrepresented students: being in their space, not on MySpace. The Reference librarian, 50: 14-28.

Alkalimat, A \& Williams, K. 2001. Social capital and cyberpower in the African American community: a case study of a community technology center in the dual city. Ann Arbor, Michigan: Alliance for Community Technology. [Online]. Available: www.communitytechnology.org/cyberpower. [Accessed 14 February 2006].

Block, M. 2000. Community outreach as a survival strategy. Ex Libris, 80, December 2000. [Online]. Available: 
http://marylaine.com/exlibris/xlib80.html. [Accessed 20 September 2011].

Butler, A. 2004. Contemporary South Africa. Basingstoke: Palgrave Macmillan.

Del Bosque, D \& Chapman, K. 2007. Your place or mine? Face-to-face reference services across campus. New Library World; 108 (5/6): 247262.

Duesing, A. 2009. Academic health sciences library outreach and a State Cancer Coalition: collaborative efforts in the cancer battle. Journal of consumer health on the Internet, 13: 237-244.

Fearless capacity. 2011. Library journal, 136 (5): 58.

Future intersections. 2006. Library technology reports, September-October 2006. [Online]. Available: www.techsource.ala.org. [Accessed 20 September 2011].

Gieskes, L. 2009. Why librarians matter to poor people. Public library quarterly, 28: 49-57.

Hart, G. 2010. New vision, new goals, new markets? Reflections on a South African case study of community library services. South African journal of libraries \& information science, 76 (2): 81-90.

Hart, G. 2011. The "tricky business" of dual use school community libraries: a case study in rural South Africa. Libri, 61 (3): 211-225

Hill, S N. 2004. Marketing for survival. Bookmobile \& outreach services, 7 (2): 43-45.

Jansen, J. 2011. In defence of books at a time when they're scorned. Times Live, 3 July 2011. [Online]. Available:

http://www.timeslive.co.za/sundaytimes/2011/07/03/in-defence-ofbooks-at-a-time-... [Accessed 23 September 2011].

Kambeitz, 2002. Are you an outreach advocate? Journal of hospital librarianship, 2 (4): 97-103.

Library \& Information Association of South Africa. 2010. LIASA Condemns the Burning down of Libraries. Press statement February 112010. http://list.liasa.org.za/pipermail/liasaonline/2010-February/002592.html [Accessed 24 June 2010].

Library and information services (LIS) transformation charter. 6th draft. 2009. Pretoria: Department of Arts and Culture (DAC) and National Council for Library and Information Services (NCLIS). [Online]. Available:http://www.dac.gov.za/publications/reports/2009/Transformati on\%20charter-6th\%20draft-22102009.pdf. [Accessed 31 January 2010].

Mehra, B \& Srinivasan, R. 2007. The Library-Community Convergence Framework for Community Action: libraries as catalysts of social change. Libri, 57 (3): 123-139. [Online]. Available: http://escholarship.org/uc/item/0mc418bg. [Accessed 20 September 2011] 
Muddiman, D. 1999. Images of exclusion: user and community perceptions of the public library. Public library policy and social exclusion working papers, working paper number 9. Leeds: School of Information Management, Leeds Metropolitan University.

Robinson, L. \& Bawden, D. 2007. Evaluation of outreach services for primary care and mental health; assessing the impact. Health information \& libraries journal, 24 (Suppl. 1): 57-66.

University of Cape Town. Development Policy Research Unit. 2010. Income and non-income inequality in post-apartheid South Africa: what are the drivers and possible policy interventions. Cape Town: University of Cape Town.

Watkins, C. 2000. News fronts ALA. Chapter report: investing in low-income neighborhoods. American Libraries, May 2000: 12.

Wiebel, K. 1983. The Evolution of library outreach 1960-75 and its effect on reader services: some considerations. Occasional paper 156 University of Illinois Graduate School of Library and Information Science. Champaign, Illinois: University of Illinois at Urbana Champaign.

Zettervall, S. 2011. When there is no frigate but a book. American libraries, January/February 2011: 48-51. 